\title{
Optical Properties of Chromium Nano Coated Films
}

\author{
D.Lakshmi, K.Gouthami
}

\begin{abstract}
Chromium Nano lined film is a layer of fabric starting from fractions These lined film layers had been utilized as hostile to reflected picture coatings on window glass, video show units and Digital cam focal points. An antireflection covering is a type of optical covering finished to the floor of focal points and distinctive optical gadgets to reduce reflection. This improves the presentation of the device because of the truth that an extraordinary arrangement significantly less light is strange of a nanometer to numerous micrometers in thickness. The general overall performance of optical tool or System is typically more advantageous whilst the thin-film coating includes more than one layer having numerous thicknesses and refractive indices.In this study, optical houses of chromium thin movies produced by the use of Spectrometer method at the Lithium Niobate substrate have been investigated. The optical houses have been researched through utilizing UV/VIS/NIR spectrophotometer. The optical constants of the Nano films are in appropriate settlement with the writing data. The solidness of the covering has been efficiently explored through selective cures.
\end{abstract}

Index Terms - Chromium coated films, Lithium Niobate, UV/VIS absorption Spectra, Band Gap, EDS

\section{INTRODUCTION}

Lithium Niobate (LiNbO3) is a compound of niobium, Lithium, and oxygen. It is a person made, certainly Birefringent, Ferroelectric material with big Pyro electric powered, Piezoelectric, Accousto optic, Electro-optic and Photo-Elastic coefficients.Its Curie temperature is 11420 C.It has extensive Transparency region (0.4-0.5 um), with a cloth attenuation of approximately zero. 05 to $0.1 \mathrm{~dB} / \mathrm{cm}$.It is chemically inert and has strong bodily and chemical houses. These residences allow applying $\mathrm{LiNbO} 3$ as material for Surface Acoustic Wave (SAW) gadgets like Filters, Oscillators and Resonators.Its spinster crystals are an important material for optical waveguides, cellular phones, optical modulators and diverse other linear and non-linear optical applications.Deposition era can properly be seemed because the main key to the introduction of devices such as computer systems.

The act of applying a Nano lined Film layers to a base is thin film deposition - any method for depositing a skinny frame of structure onto a substrate or onto previously deposited layers. "Nano"is a relative term; however maximum deposition strategies manipulate layer thickness inside a few tens of nanometers.

\section{EXPERIMENTAL}

Chromium has an excessive Infiltration proportion in a gigantic wavelength runs from the $120 \mathrm{~nm}$ bright beam in a

Revised Manuscript Received on April 12, 2019.

D.Lakshmi,Electronics and Inst. Tech, AchryaNagarjuna University, Guntur.A.P, India.

Dr.K.Gouthami, Department of Electronics, MalineniLakshmaiah women's Eng. College, Guntur,A.P, India. vacuum to the $900 \mathrm{~nm}$ infrared beam. Economically accessible chromium is utilized as a covering material. Ultrasonically cleaned Lithium Niobate substrate was utilized as a substrate. The coating was carried out for single layer of thickness $1800 \mathrm{~A}^{\circ}$ and a second layer of thickness $3000 \mathrm{~A}^{\circ}$ was done.

Evaporation is a commonplace approach of thin film deposition.The supply material is evaporated in a vacuum. The vacuum lets in vapor particles to journey directly to the goal object, in which they condense returned to a stable state.

\section{A. Optical absorption Studies}

The trivalent Chromium particle in an octahedral symmetry gives upward push to a couple of huge groups' whose dimensions are because of advances among the 4 quarter.The optical spectra of chromium coating on $\mathrm{LiNbO} 3$ in the wavelength vicinity $300-800 \mathrm{~nm}$ is shown in Graph.1.The optical spectra consists of three bands at $360 \mathrm{~nm}$, a vulnerable band $\sim 440 \mathrm{~nm}$, and a vast band at $615 \mathrm{nmwhich}$ might be in appropriate settlement with the literature (IOP Science 2013 Phys. Scr.87.055602). The determined bands are traits of $\mathrm{Cr}+2$ ions in octahedral symmetry.A new band is discovered at $275 \mathrm{~nm}$ inside the UV absorption place may be attributed to the rate switch transitions of the $\mathrm{Cr}+2$ ion.

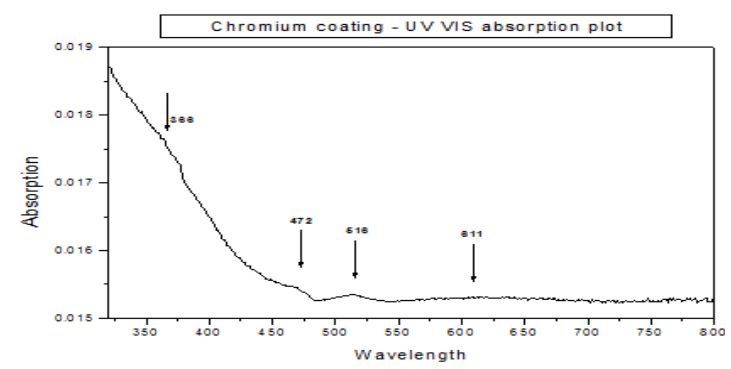

Graph.1.Absorption plot of chromium (UV, VIS)

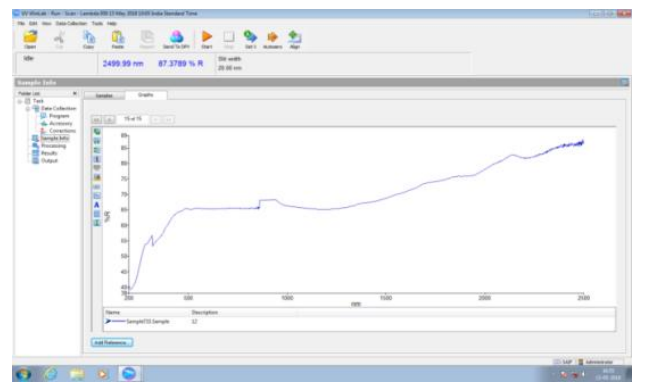

Graph.2. UV-VIS -NIR Spectra of Chromium coating on LiNbO3 sample

Published By:

Blue Eyes Intelligence Engineering

\& Sciences Publication 


\section{B. Optical band Gap}

The optical band gap is an essential device to clarify the idea of the solid nation laser fabric. Optically caused advances and the optical band gap estimations of Chromium dainty nano films on $\mathrm{LiNbO} 3$ can be determined from the optical retention spectra. In glasses, the conduction band is roused by method for the glass framing anions and the feline particles play an angled anyway huge position. There are two assortments of optical advances which incorporate immediate and slanted changes. The optical assimilation coefficient $\alpha(v)$ near the fundamental ingestion edge changed into chose through the utilization of the connection.

$$
\alpha(v)=(1 / d) \log \left(I_{0} / I_{t}\right)
$$

Where I0 and It are the forces of the episode and transmitted pillars, $d$ is the thickness of the example. The part $\log (\mathrm{I} 0 / \mathrm{I} \mathrm{t})$ compares to the absorbance. Assimilation coefficient $\alpha(v)$ as an element of photon power hv for immediate and aberrant permitted changes can be communicated through the connection

$$
\alpha(v)=B\left(h v-E_{\text {opt }}\right)^{n / h v}
$$

Where $\mathrm{B}$ is the holding parameter and ho is the photon imperativeness, the record $n=1 / 2$ for direct allowed advances and $n=2$ for meandering advancement. By plotting ( $\alpha$ hu) ${ }^{1 / 2}$ and $(\alpha \text { hv })^{2}$ versus huthe optical essentialness band opening ( $E$ select) for quick and underhanded advances can be resolved. The estimations of $\mathrm{E}$ pick are obtained by extrapolating to $(\alpha \cup \mathrm{h})^{1 / 2}=0$ for circuitous and $(\alpha \text { hv })^{2}=0$ for direct changes.

Underneath fig. speaks to Tauc's plots of the $(\alpha \text { hv })^{2}$ and $\left(\alpha\right.$ h) ${ }^{1 / 2}$ for chromium slight film on LiNbO3 and the estimation of $\mathrm{E}$ select are observed to be 3.30 for unadulterated $\mathrm{LiNbO} 3$ it is $3.7 \mathrm{eV}$

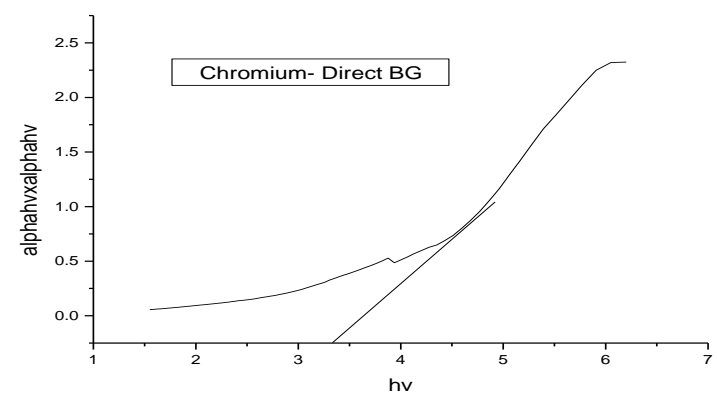

Graph.3.Direct B.G. of Chromium

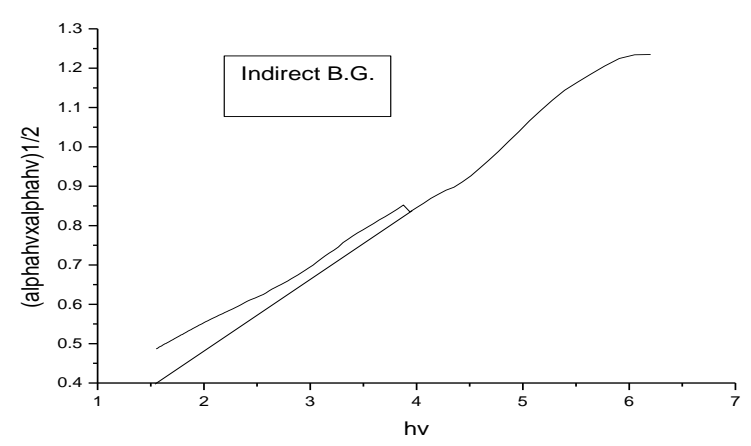

Graph .4.Indirect B.G of Chromium

\section{Energy Dispersive Spectrums(EDS)}

Below fig. demonstrate an ordinary EDS Spectrum gained with a SEM. It is made out of pinnacles comparing to explicit X-beam lines. The range demonstrates the nearness of $\mathrm{O}, \mathrm{Nb}$, and Chromium in the covered film. EDS Spectrum has affirmed the presence of $\mathrm{O}, \mathrm{Nb}$ and $\mathrm{Cr}$ in the covered movies.

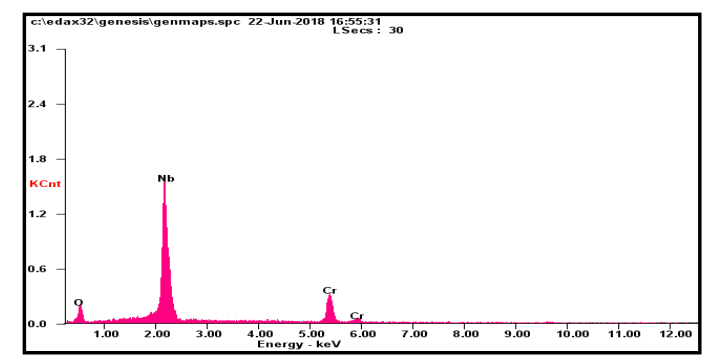

Graph.5.EDS of Chromium Coated Films

\begin{tabular}{|c|c|c|}
\hline Element & Wt\% & At $\%$ \\
\hline OK & 21.22 & 53.14 \\
\hline NbL & 64.07 & 31.58 \\
\hline CrK & 17.36 & 15.29 \\
\hline Matrix & Correction & ZAF \\
\hline
\end{tabular}

Table.1.Wt\% At\% values of $\mathrm{O}, \mathrm{Nb}, \mathrm{Cr}$

\section{RESULTS}

From graph.1 and 2 another band is seen at $275 \mathrm{~nm}$ in the UV ingestion district might be ascribed to the charge exchange changes of the $\mathrm{Cr}+2$ particles. From Graph 3 and 4 It is seen that optical band gap vitality diminishes with increment in fixation. This is because of basic changes that are occurring in the glass arrange. Chart 5 demonstrates the nearness of $\mathrm{O}, \mathrm{Nb}$, and Chromium in the covered film. EDS Spectrum has affirmed the presence of $\mathrm{O}, \mathrm{Nb}$ and $\mathrm{Cr}$ in the covered films.

\section{CONCLUSION}

We finish up this paper with Absorption properties of chromium Nano film kept on LiNiO3, Optical vitality band Gaps, and Energy Dispersive Spectrums. Charge exchange changes of the $\mathrm{Cr}+2$ particles are seen in the $\mathrm{UV}$ ingestion range. The watched groups are attributes of $\mathrm{Cr}+2$ particles in octahedral symmetry. It is seen that optical band gap vitality diminishes with increment in focus. EDS Spectrum has affirmed the presence of $\mathrm{O}, \mathrm{Nb}$ and $\mathrm{Cr}$ in the covered movies. The hypothetical qualities wt $\%$ and At $\%$ has been determined for $\mathrm{Cr}, \mathrm{NbL}, \mathrm{O}$ and is in great concurrence with the hypothetical qualities.

\begin{tabular}{|l|l|l|l|l|}
\hline Element & $\begin{array}{l}\text { Wt \% } \\
\text { Exp.) }\end{array}$ & $\begin{array}{l}\text { Wt\% } \\
\text { (Theo. })\end{array}$ & $\begin{array}{l}\text { At\% } \\
\text { Exp.) }\end{array}$ & $\begin{array}{l}\text { At \% } \\
\text { (Theo.) }\end{array}$ \\
\hline OK & 21.22 & 32.45 & 53.14 & 60 \\
\hline NbL & 64.07 & 66.86 & 31.58 & 40 \\
\hline CrK & 17.36 & 26.01 & 15.29 & 20 \\
\hline
\end{tabular}

Table.2.comparision of theoretical and Practical values

Published By: Blue Eyes Intelligence Engineering 


\section{REFERENCES}

1. H.a. Macleod,Adam Hilger Ltd.,London,2001, p9E.D.

2. Coordination and ion-ion interactions of chromium centers in alkaline earth zinc borate glasses probed by electron paramagnetic resonance and optical spectroscopy IOP Science (http://iopscience.iop.org/1402-4896/87/5/055602)

3. Patent U.S. 3600243 Method of making chromium mask for photoresist applications

4. Handbook ofThin Film Deposition. Pdf

5. Principles of Physical Vapor Deposition of Thin FilmsK. Harsha

6. Pulsed Laser Deposition of Thin Films , REason (Wiley,2007)

7. T.Yoshida,K.Nishimoto,K.Sekine and K.Etoh,Appl.Opt. 45,1375 (2006)

8. Material Science of Thin films(Magnetron Sputtering PvdCvd Surface).pdf

9. S.Niisaka,T. Saito,J.Saito,A. Tanaka,A. Matsumoto,M. Otani,R. Biro,C.Ouchi,M.Hasegawa, Y. Suzuki and K.Sone,Appl.Op. 41,3242 (2002).

10. K.L. Chopra 'Thin film Phenomena',McGraw Hill,New York(1969).

11. Seraphin, B.O.(1974), chemical vapor deposition for fabrication of solar energy converter, National Science foundation.Rept. SE/G1, 3673 .

12. MacLeod,B.D., and Hobbs,D.S.,":Low-Cost Anti - Reflection Technologyfor Automobile Displays", Journal of the Society for Information Display,Automotive Display Conference, November 2004.

13. Macleod, A., 1999, The Early Days of Optical Coatings, J.Opt.A:Pure Appl. Opt. 1, P:779-783. 